\title{
LA AVALANCHA DE LOS DATOS EN LA PRÁCTICA Y LA COMUNICACIÓN CIENTÍFICAS: RIESGOS E INCERTIDUMBRES
}

\section{THE DATA AVALANCHE IN SCIENTIFIC PRACTICE AND COMMUNICATION: RISKS AND UNCERTAINTIES}

\author{
Miguel Ángel Medina Torres \\ (Universidad de Málaga) \\ medina@uma.es
}

Recibido: 3 de enero 2021 / Aceptado: 25 de febrero 2021

\begin{abstract}
Resumen: La nueva era del Big Data en la que estamos inmersos abre camino a nuevas oportunidades, pero también a nuevos riesgos e incertidumbres. En el campo de las ciencias y su comunicación, la acumulación masiva de datos asociada al Big Data se está convirtiendo en uno de los grandes retos y uno de los principales riesgos para el propio progreso de la actividad científica. La hiperinflación de las publicaciones científicas, el poder de decisión cada vez mayor de los editores a la hora de determinar qué publicar y qué no, el castigo a las clases medias de la ciencia en momentos de incertidumbre económica y la ausencia del tiempo necesario para la reflexión son algunos de los males que aquejan a la ciencia contemporánea en esta era del Big Data. En el presente artículo, reflexiono sobre todo ello estableciendo una crítica acuciantemente necesaria al presente quehacer de los científicos.
\end{abstract}

Palabras clave: Big Data, publicaciones científicas, revisión por pares, clases medias de la ciencia, reflexión

\begin{abstract}
The new era of Big Data in which we are immersed opens the way to new opportunities, but also to new risks and uncertainties. In the field of science and its communication, the massive accumulation of data associated with Big Data is becoming one of the great challenges and one of the main risks for the progress of scientific activity itself. The hyperinflation of scientific publications, the increasing power of decision of the editors when determining what to publish and what not to publish, the punishment of the middle classes of science in moments of economic uncertainty and the absence of the necessary time for reflection are some of the evils that afflict contemporary science in this era of Big Data. In this article, I reflect on all this by establishing a critique that is urgently needed of the present work of scientists.
\end{abstract}


Keywords: Big Data; scientific publishing; peer-review; science middle classes; reflection

\section{Introducción}

La humanidad está inmersa en plena era del Big Data. Este hecho objetivo es fuente de nuevas oportunidades, pero, simultáneamente, nos enfrenta a nuevos riesgos e incertidumbres. En un mar de datos, ¿cómo navegar seguros sin perdernos?

En lo que llevamos del nuevo milenio, la humanidad ha entrado en la era del Big Data y actualmente está inmersa en ella. Cuando hablo de Big Data me refiero simultáneamente a la acumulación masiva de datos en bases de datos, las tecnologías que generan estos datos, las tecnologías que permiten usarlos y toda la (cada vez más) extensa metodología asociada. En español, se va introduciendo cada vez más el término Ciencia de Datos para referirse a ello. La acumulación masiva de datos que propicia la tecnología asociada al Big Data está creando nuevos escenarios antes inexplorados que están abriendo campo a una lista creciente de nuevas oportunidades en diversos ámbitos del quehacer humano, incluyendo las tecnologías humano-centradas y las actividades económicas y científicas. Pero, al mismo tiempo, este nuevo mar de datos en el que no siempre es seguro navegar y donde fácilmente podemos perdernos nos enfrenta a nuevas incertidumbres y todo un conjunto de insospechados riesgos.

Soy, de formación, biólogo. La revolución científico-tecnológica del ADN recombinante y los organismos modificados genéticamente y las tecnologías «ómicas», muchas de ellas con resolución de célula e incluso de molécula individual, han convertido a la biología en ciencia de frontera en el momento actual. Estas circunstancias han propiciado que la investigación biológica se convierta en una de las actividades científicas que actualmente contribuyen más decisivamente al crecimiento del Big Data.

En el presente artículo, uso el conocimiento que desde dentro poseo del estado actual de la investigación y la comunicación científica en el campo de las ciencias biológicas para reflexionar acerca de algunos de los males que aquejan a la ciencia contemporánea en esta era del Big Data. La lista de tales males es extensa e incluye a la hiperinflación de las publicaciones científicas, el poder de decisión cada vez mayor de los editores a la hora de determinar qué publicar y qué no, el castigo a las clases medias de la ciencia en momentos de incertidumbre económica y la ausencia del tiempo necesario para la reflexión acerca de nuestro propio quehacer como científicos. Esta lista de problemas que actualmente afronta el quehacer investigador y la comunicación científica cómo la acumulación de datos en la 
práctica científica y en la comunicación de la ciencia se está convirtiendo en uno de los grandes retos y uno de los principales riesgos para el propio progreso de la actividad científica. En el presente artículo, reflexiono sobre todo ello estableciendo una crítica acuciantemente necesaria al presente quehacer de los científicos. Aunque Big Data presenta también importantes retos tanto metodológicos como epistemológicos (Kitchin 2014), estos aspectos no serán analizados aquí.

\section{La avalancha de los datos publicados}

La digitalización de los datos es una realidad en un mundo cada vez más digital. La cantidad de datos que se están recopilando y convirtiendo a formato digital sumada a la ingente cantidad de nuevos datos generados directamente en formato digital contribuyen decisivamente al crecimiento exponencial del Big Data. La denominada ley de Moore de los datos establece que en el momento actual más del $90 \%$ de todos los datos disponibles en formato digital fueron creados u obtenidos en los últimos dos años (www.idc.com). Esta es la auténtica avalancha de los datos y esta es la causa de la creciente brecha existente en el conocimiento humano, porque los datos en bruto no se han convertido todavía completamente en información, ni esta ha sido totalmente procesada hasta rendir auténtico nuevo conocimiento. La Figura 1 (adaptada de una figura original de Dieter Mart) muestra que la creciente velocidad con la que se acumulan los datos hace crecer: $1^{\circ}$ La brecha que separa a los datos acumulados de la cantidad de estos que se convierte en información (conversión que se produce a una velocidad mucho menor). $2^{\circ} \mathrm{Y}$ aún más la brecha que separa a estos datos acumulados de un nuevo conocimiento (dado que la velocidad a la que crece nuestro conocimiento y su utilidad en dominios específicos de nuestra actividad humana es mucho más lenta). [Fig. 1]

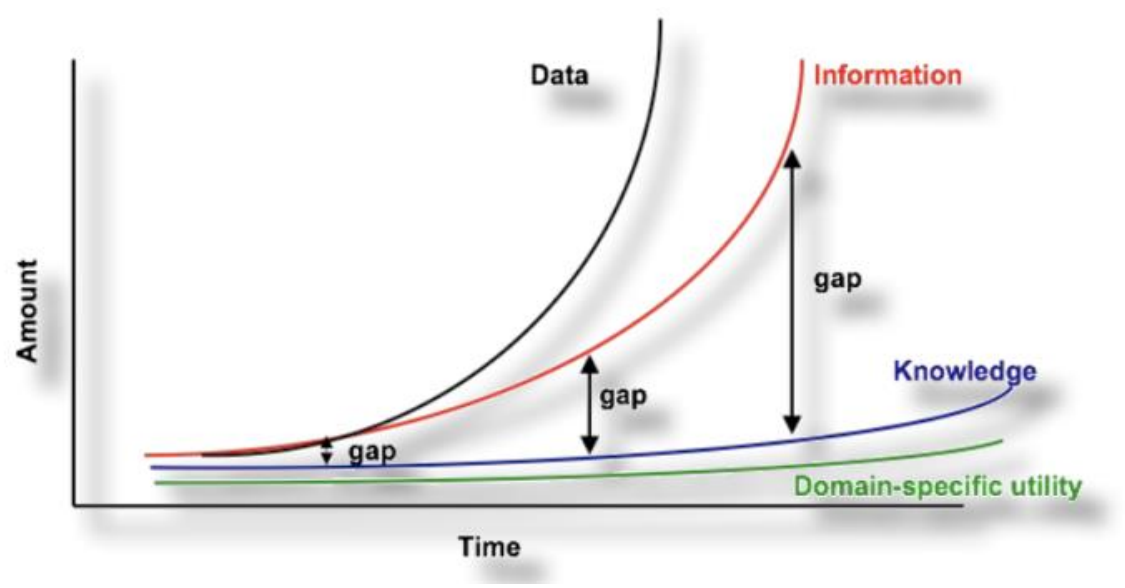

Fig. 1: La brecha creciente entre datos, información y conocimiento 
En la actividad de comunicación de la ciencia queda muy clara una de las causas y consecuencias de la brecha arriba mencionada: la hipertrofia de las publicaciones científicas. En la actualidad se editan más de doce mil revistas científicas indexadas en Journal Citation Report (JCR) y muchísimas más no indexadas, aparte de la plaga creciente de las publicaciones piratas. El número de artículos y páginas que estas revistas científicas serias e indexadas publican aumenta año tras año, así como la extensión media de cada artículo publicado y el contenido total de datos en cada uno de ellos.

Un fragmento de $A$ través del espejo (la segunda de las aventuras de Alicia ideadas por Lewis Carroll) inspiró tiempo atrás la formulación del llamado efecto Reina Roja y su uso en distintos ámbitos de las ciencias (Van Valen 1973). Dicho fragmento es el que sigue:

Alicia no podía explicarse cómo comenzó aquella extraña carrera. Lo único que recordaba es que corría de la mano de la Reina y ésta se desplazaba a tal velocidad que la niña apenas podía seguirla. La Reina no cesaba de gritar: “¡Deprisa! ¡Más deprisa! (...) Y lo más curioso de todo era que, por más que corrían, los árboles y los otros objetos a su alrededor no se movían de sitio (...).

Y tan deprisa iban que parecía que se deslizaban por los aires sin apenas tocar el suelo con los pies. Cuando Alicia creía que había llegado al último suspiro, se detuvieron y se encontró sentada en el suelo, mareada y casi sin aliento.

La Reina le ayudó a recostarse contra el tronco de un árbol y le dijo amablemente: -Puedes descansar un rato.

Alicia miró a su alrededor sorprendida: -jPero si estamos donde estábamos antes! ¡No nos hemos movido de este árbol! ¡Todo está igual que antes!

- ¡Pues claro que sí! - exclamó la Reina-. ¿Cómo iba a estar si no?

-En mi país -dijo Alicia, que todavía jadeaba un poco al hablar-, cuando se corre durante algún tiempo en una determinada dirección se suele llegar a alguna parte.

-Tu país debe ser algo lento - comentó la Reina-. Aquí tienes que correr a toda velocidad para poder permanecer en el mismo lugar y, si quieres desplazarte a otro... jentonces debes correr el doble deprisa!

El efecto Reina Roja ilustra cómo en diversos ámbitos la única forma de, al menos, mantenerse en el sitio es «correr mucho». También en el mundo de la comunicación científica puede aplicarse este efecto, dado que a los grupos de investigación se les exige cada vez más. Simplemente para no quedarse atrás, los grupos de investigación tienen que hacer unos esfuerzos crecientes para ofrecer más nuevos datos en menos tiempo. Permítanme que ilustre 
estas circunstancias (que suponen una presión creciente para los grupos de investigación) con el caso que conozco mejor: la evolución del grupo de investigación al que pertenezco. Lo haré escogiendo tres publicaciones representativas de nuestro quehacer científico. En 1988 publicamos en la prestigiosa revista británica Biochemical Journal (en aquel tiempo situada en el primer cuartil de su área en JCR) un artículo de investigación de 5 páginas, que contenía 4 figuras simples (cada una con un único panel) y una tabla (Quesada et al., 1988). En 2009, publicamos en el British Journal of Pharmacology (en el primer decil de su área en JCR) un artículo de investigación de 8 páginas, que contenía 6 figuras (con un total de 14 paneles) y una tabla (Melgarejo et al., 2009). En 2020, un artículo de investigación de nuestro grupo publicado en Food Chemistry (en el primer decil de su área en JCR) tenía una extensión de 8 páginas y constaba de 9 figuras (con un total de 45 paneles), dos tablas y 6 vídeos (Marrero et al., 2020). En resumen, se nos ha ido exigiendo un esfuerzo investigador creciente, sin ir ello acompañado de un aumento proporcional en la financiación de nuestra investigación, y todo ello simplemente para mantener el nivel de nuestras publicaciones.

Esta inflación del contenido «bruto» de información de los artículos científicos ha sido generalizada, como ejemplifica claramente los siguientes ejemplos tomados de una de las revistas científicas más serias, rigurosas, prestigiosas y antiguas: la británica Nature. En abril de 1953 esta revista publicaba tres brevísimos artículos sobre la estructura tridimensional de la molécula portadora de la información biológica, el ácido desoxirribonucleico o ADN. Entre ellos, se encontraba el famoso artículo de Watson y Crick de una página de extensión que aportaba el icónico primer dibujo de la doble hélice del ADN como única figura (Watson \& Crick, 1953). Un artículo en el campo de la metástasis tumoral publicado en 2020 en la misma revista Nature (Ubellacker, Tasdogan, Ramash et al., 2020) ocupaba 8 páginas (más 16 páginas adicionales de información suplementaria) y contenía 1 tabla, 3 figuras (con 37 paneles), más dos tablas suplementarias de extended data y otras 6 figuras suplementarias de extended data (con 50 paneles).

La presión por publicar, cada vez más acentuada en mi campo, conduce a la «pescadilla que se muerde su cola» del «publica o perece» [Fig. 2]. 


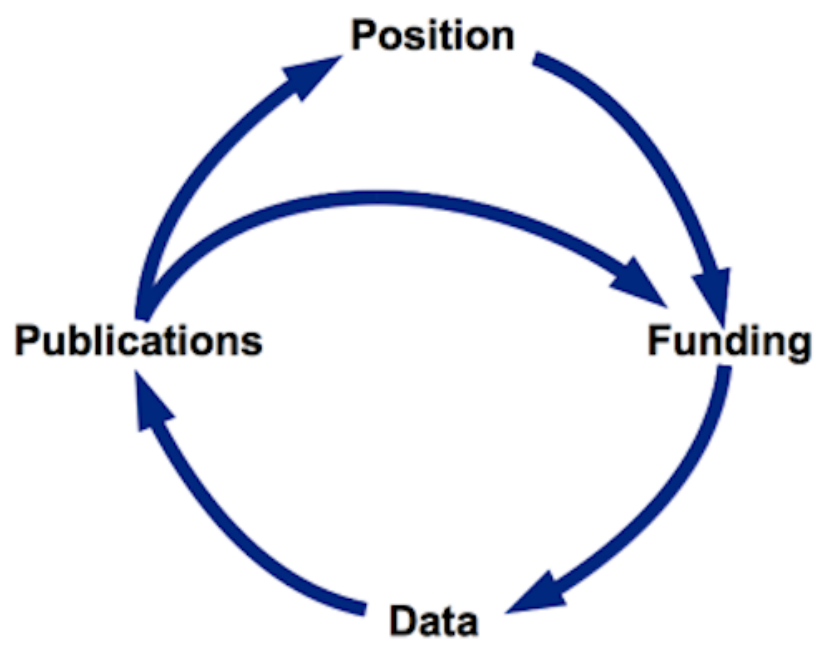

Fig. 2: La «pescadilla que se muerde la cola» del «publica o perece»

Desde este punto de vista, mayoritariamente la actividad de los grupos científicos se describe de esta forma resumida: buscamos acumular datos nuevos que nos garanticen publicaciones que nos permitan aspirar a una mejor o más estable posición profesional y a nuevos fondos que financien nuestras futuras investigaciones para acumular más datas que conduzcan a nuevas publicaciones y así sucesivamente. O sea, corremos alocadamente sobre una rueda sin movernos del sitio. De nuevo como Alicia, en este delicioso fragmento de En el pais de las Maravillas:

-¿Podría usted indicarme la dirección que debo seguir desde aquí?

-Eso depende -le contestó el Gato- de adónde quieras llegar.

-No me importa adónde -empezó a decir Alicia...

- En ese caso, tampoco importa la dirección que tomes -le dijo el Gato-.

- ...con tal de llegar a algún lado -acabó de decir Alicia.

- Eso es fácil de conseguir -le dijo el Gato-. ¡No tienes más que seguir andando!

\section{La mercantilización de la ciencia}

En la actualidad, cuesta realizar investigación básica «pura», pues cada vez más las entidades y organismos financiadores exigen «rentabilidad» a la investigación científica y prima la investigación inmediatamente aplicable y con perspectivas de rendir beneficios económicos a corto o medio plazo. Asistimos, pues, a una creciente mercantilización de la ciencia, que afecta a todas las facetas de la actividad investigadora, incluyendo el momento de su publicación en revistas científicas. Este acuciante problema ha sido abordado en profundidad 
por los autores de los diversos capítulos del libro The Commodification of Academic Research: Science and the Modern University (Radder, ed., 2010). Cada vez son más las revistas que ofrecen un sistema aparentemente beneficio de acceso libre sin restricciones a cuantos tengan conexión a Internet. Sin embargo, en realidad el coste de mantenimiento de este sistema de libre acceso recae sobre los propios investigadores, a quienes se nos exigen unos «costes de procesamiento de los artículos» que oscilan entre varios cientos y varios miles de euros por artículo, según el grupo editor y la revista en que vayan a ser publicados. Sorprendentemente, los investigadores hemos consentido en convertirnos en un rarísimo grupo de profesionales que... ipagan por el trabajo que hacen!

Esta mercantilización de la ciencia está ligada a la explotación que sufren los integrantes «de base» de los grupos científicos, esos becarios/precarios, contratados pre/postdoctorales que malviven con decientes condiciones contractuales y muy reducidas expectativas de estabilización laboral hasta edades impensables en otros ámbitos de actividad laboral. Y la cosa puede ser aún peor: cada vez más científicos colegas nuestros confunden su quehacer (y, jojo!, el de su grupo) con una especie de «sacerdocio» por el que hay que sacrificarlo todo, por el que hay que estar disponible 24 horas al día, 7 días a la semana, a riesgo de que te discriminen a la hora de fijar posiciones en las publicaciones o de renovar contratos. Y así es como se ha llegado a la situación actual de que muchos grupos nacionales e internacionales de muy alto impacto científico mantienen su posición a costa de que el investigador director del grupo ejerza un poder omnímodo y absoluto, explotando tantas veces a los miembros de su equipo con exigencias propias de caciques de «su cortijo».

\section{Un requiem por la revisón entre pares}

A los científicos se nos licúa la boca para proclamar orgullosamente que el sistema de peer review (de revisión «entre pares») que nos hemos otorgados es el más justo y el que mejor puede filtrar la ciencia que realmente merece la pena. ¿Pero es esto realmente así? ¿Realmente son colegas científicos como nosotros los que utilizando criterios exclusivamente científicos juzgan la calidad de nuestro trabajo y deciden si merece ser publicado o no? Si esto alguna vez fue así, cada vez está más alejado de la real práctica de las editoriales y revistas científicas en la actualidad. En los últimos diez años, en las políticas editoriales de cada vez más revistas científicas la revisión «entre pares» solo queda para los casos de los manuscritos que han superado previamente otros filtros (mayoritariamente, acientíficos y discrecionales) que dan un poder a los editores que nunca debieron tener. En muchos casos, los editores ejercen una 
poderosa dictadura, a la que no es ajena la práctica del «amiguismo», ni los juegos de presión más mediáticos, políticos y económicos que científicos.

¿Quién puede/debe decidir qué ciencia merece ser publicada? El Dr. Frederick L. Crane (1925-2016), un grande de la ciencia (a pesar de ser poco conocido, muy probablemente por su gran modestia personal), lo tenía muy claro: toda ciencia buena, toda ciencia bien hecha, merece ser publicada. Autor del importante descubrimiento de la coenzima Q en 1957 y líder mundial indiscutible de las investigaciones sobre los sistemas de transporte electrónico de membrana plasmática en el último cuarto del siglo XX y principios del siglo XXI, con más de 500 artículos publicados, el Dr. Crane era la antítesis de los abundantes engreídos y «divos» de la ciencia, autoproclamados «pontífices» de su «sacerdocio»: sencillo, modesto, riguroso en su trabajo callado y sin aspavientos. [Fig. 3]

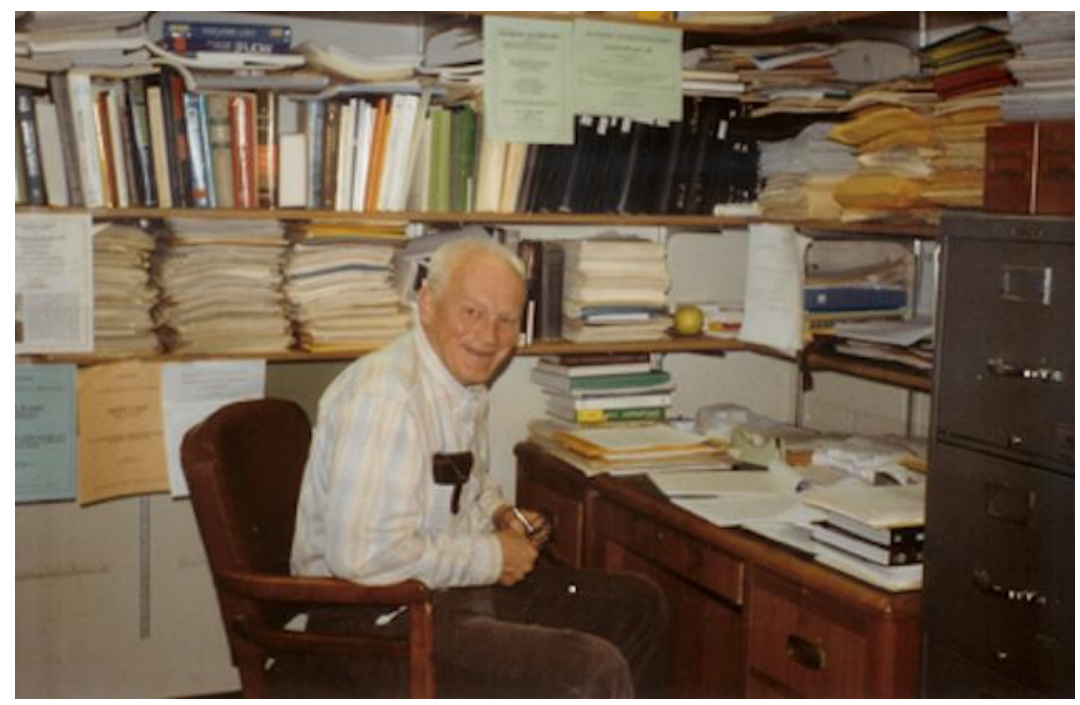

Fig 3. Frederick L. Crane (1925-2016)

Tuve la oportunidad, la suerte y la inmensa honra de conocer personalmente al Dr. Crane en los años 80 y 90 y todavía recuerdo con cariño la conferencia que impartió en nuestra Facultad, invitado por el que entonces era director de mi Departamento, y haciendo uso exclusivamente de su vOz y de sencillas transparencias bosquejadas por él mismo en una época en la que la mayoría de las conferencias científicas se impartían apoyadas en diapositivas proyectadas.

Lamentablemente, los vientos actuales de la industria editorial científica soplan en sentido opuesto a los postulados del Dr. Crane: los criterios de «originalidad», «relevancia»y de «oportunidad» (estar más o menos de moda) son los predominantes criterios discrecionales (y acientíficos) usados por los editores para decidir qué artículos enviar a 
revisión entre pares. $\mathrm{Y}$ todo ello a pesar de que la experiencia previa demuestra que en muchos casos grandes descubrimientos científicos fueron publicados en revistas modestas. Manfred Eigen (Premio Nobel de Química en 1967) publicó los fundamentos teóricos de la evolución molecular dirigida de proteínas en la modesta revista Pure and Applied Chemistry en 1984 (Eigen \& Gardiner, 1984). Nueve años después, la Dra. Frances H. Arnold hacía público el flujo de trabajo y los resultados que había obtenido en la aplicación de esos principios para conseguir experimentalmente la evolución molecular dirigida y controlada en el laboratorio de la enzima subtilisina E (Chen \& Arnold, 1993). Este trabajo, hoy día considerado seminal en su área, hizo a la Dra. Arnold merecedora del Premio Nobel de Química 2018 (compartido con George Smith y Gregory Winter).

\section{La destrucción de la clase media de la investigación}

La «carrera de obstáculos» por alcanzar fondos que financien nuestras líneas de investigación alcanza tintes dramáticos en momentos de crisis económica. El caso español es especialmente demoledor. La realidad de la política científica de nuestro país es que no existe una política de estado con amplio consenso de la importancia del apoyo a la ciencia para el progreso del país. Múltiples indicadores e informes así lo confirman. El pasado mes de abril de 2019, la revista Investigación y Ciencia publicaba el artículo «La política científica española, en el atolladero», firmado por la Dra. Aurelia Modrego Rico (2019), quien en el pasado fue directora adjunta de la ANEP y subdirectora general de Promoción General del Conocimiento. En dicho artículo, la Dra. Modrego hace una lúcida y contundente disección de la penosa situación actual de la política científica en España. Los datos numéricos son desoladores. La inversión total en $\mathrm{I}+\mathrm{D}+\mathrm{i}$ en España se sitúa ligeramente por encima del 1\% del PIB, cuando la media de la UE casi duplica ese valor y un país como Alemania se acerca al 3\%. Durante los años más duros de la más reciente crisis económica de la que no terminamos de salir, durante el periodo 2009-2013 la dotación pública para I+D+i en España se redujo en un $38,7 \%$, y -a pesar del crecimiento de dicha dotación en los dos últimos añostodavía en 2018 los 7062 millones de euros disponibles estaban lejos de alcanzar los 9673 millones disponibles en 2009. Tristemente, en nuestro país la $\mathrm{I}+\mathrm{D}+\mathrm{I}$ no se considera una inversión, sino un gasto prescindible. En palabras de la Dra. Modrego:

La reducción sistemática de la financiación pública de la ciencia en los años de crisis se ha convertido en la marca española de la política científica. Este comportamiento es totalmente opuesto al de otros países europeos como Alemania (... con) una visión de la investigación 
científica y el desarrollo tecnológico como inversiones a medio y largo plazo (... y) factores imprescindibles para salir de la crisis.

En todas las crisis económicas, quienes más sufren sus consecuencias son las clases medias, que se empobrecen, incrementando el abismo entre los pocos que tienen mucho y los muchos que tienen cada vez menos. Esto, que vale para la sociedad en general, es también estrictamente cierto cuando nos referimos a la ciencia. En España, la crisis ha golpeado durísimamente a la ciencia y esto ha afectado a todos, pero los más afectados han sido los pertenecientes a las «clases medias de la ciencia», de forma que desde 2008 hasta la fecha docenas de grupos asentados y con un historial decente de publicaciones han desaparecido.

\section{A modo de conclusión: por una ciencia lenta con tiempo para madurar y reflexionar}

A lo largo del presente artículo, he reflexionado sobre algunos de los riesgos que corre la actual actividad científica como agente para la acumulación masiva de datos. La alocada carrera por generar más y más datos en menos tiempo, por publicar más y más rápido nos arrebata a los científicos el tiempo y la tranquilidad necesarios para reflexionar adecuadamente sobre qué estamos haciendo, cómo, por qué y para qué. Pero sin tiempo para reflexionar no es posible hacer una buena ciencia, pues la ciencia buena (como los buenos vinos) necesita de tiempo para madurar adecuadamente. [Fig. 4]

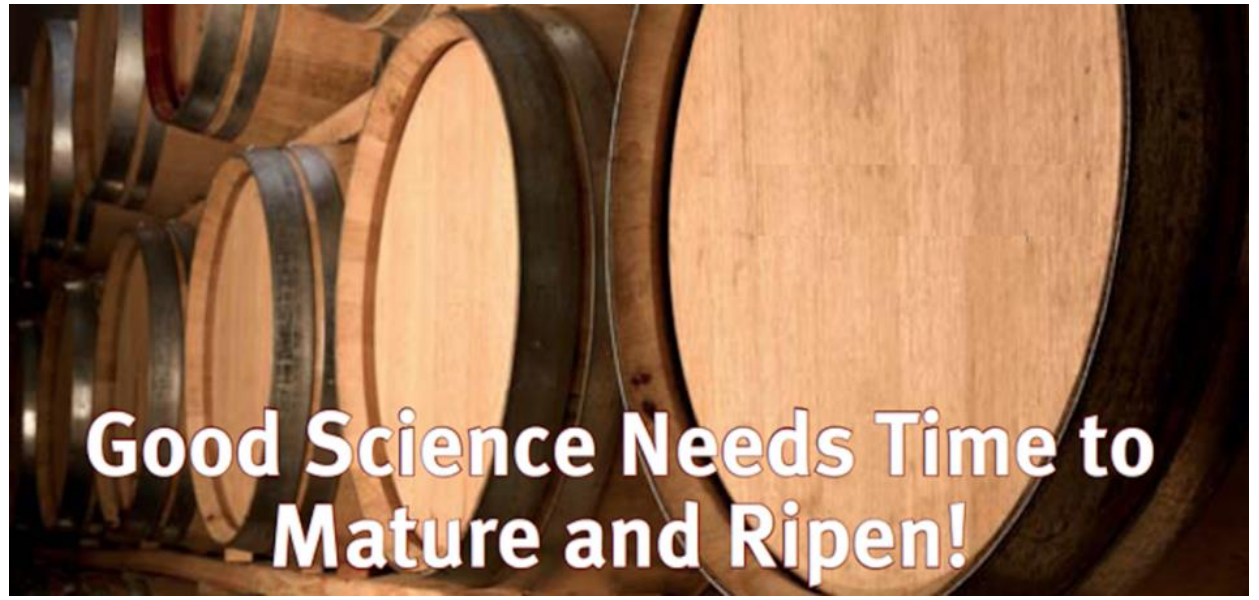

Fig. 4: La buena ciencia necesita, como el buen vino, tiempo para madurar. Imagen publicada en el segundo número de 2012 de la revista Lab Times

En respuesta a estas carencias, se ha gestado y se está desarrollando un movimiento (todavía muy minoritario, pero en proceso de franca y paulatina expansión) que aboga por una forma más pausada, más humana, más reflexiva de hacer ciencia, por una ciencia lenta (Garfield, 1990; Kahneman, 2012; Stengers, 2017). 
Conviene no olvidar que, frente a esta avalancha de datos, de artículos científicos, se contrapone la belleza y la verdad desnuda de la simplicidad, presentes en el genuino conocimiento científico. Belleza y verdad encerrados en simples y poderosas ecuaciones matemáticas que sintetizan principios fundamentales y en esquemas que han llegado a convertirse en icónicos, como ponen de manifiesto los ejemplos recogidos en los dos paneles reproducidos de la revista de pensamiento y cultura general Paradigma (Autor, 2014).

[Paneles 1 y 2]

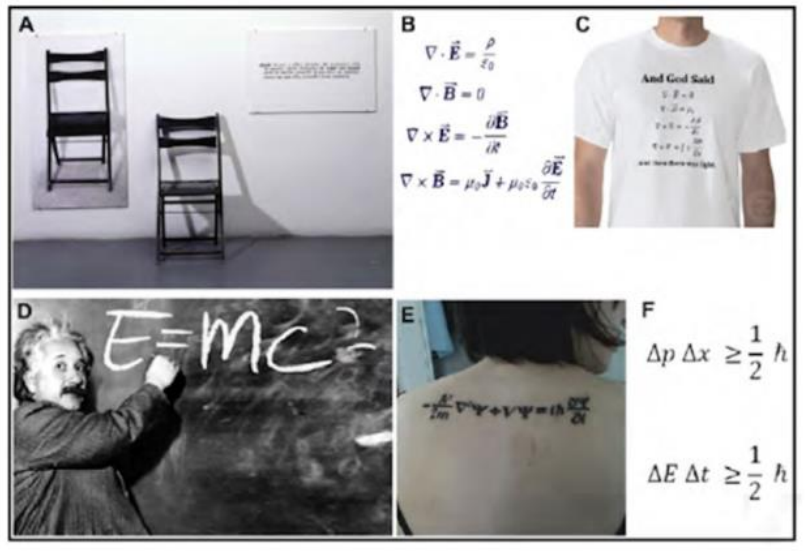

Panel 1. (A) Reproducción fotografica de la versión de Una y tre sillas (Joseph Kosuth, 1965) instalada en el Museo Nacional de Arte Contemporíneo Reina Sofia (Madrid). (B) Ecuaciones de Maxwell. (C) Las ecuaciones de Maxwell estampadas en uma camiseta, con el lema \&Y Dios dijo ... (ecuaciones)... y se hizo L luž. (D) Einstain escribiendo en la pizarra su Gmosa cuación. (E) Ecuación de ondas de Erwin Werner Heisenberg.

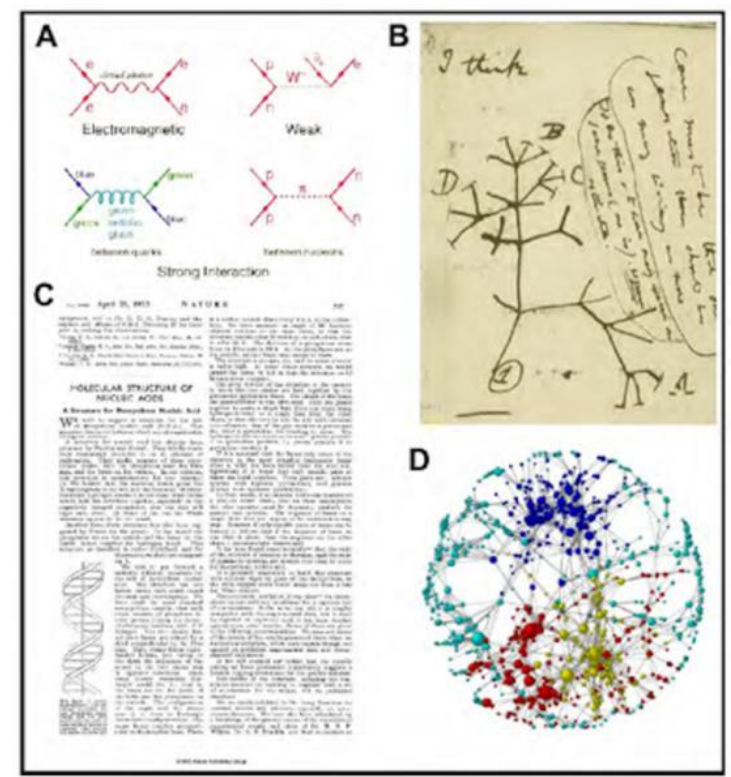

Panel 2. (A) Diagramas de Fonnman. (B) Cadograma de Charles Darwin. (C) Primera pegína del breer articulo de Watson y Crick de 1953 que contiene d primer dibejo de la doble halice. (D) Representación simbólica (abrerracán) en red de un sistema constitutido por una sené de componentes y sus coneciones Los nodos de ta red representan los distintos componentes del sisema Los disintos colores de los nodor

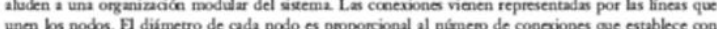
otros nodos. 


\section{Referencias bibliográficas}

Chen, K.; Arnold, Frances H. (1993). Tuning the activity of an enzyme for unusual environments: sequential random mutagenesis of subtilisin $E$ for catalysis in dimethylformamide. Proceedings of the National Academic of Sciences USA, 90, 5618-5622.

Eigen, Manfred; Gardiner, William (1984). Evolutionary molecular engineering based on RNA replication. Pure and Applied Chemistry, 56, 67-978.

Garfield, Eugene (1990). Fast science vs. slow science, or slow and steady wins the race. The Scientist, 4(18), 14.

Kahneman, Daniel (2012). Thinking Fast and Slow. London: Macmillan.

Kitchin, Rob (2014). Big Data, new epistemologies and paradigm shifts. Big Data \& Society, April-June, 1-12.

Marrero, Ana Dácil; Castilla, Laura; Espartero, José L.; Madrona, Andrés; Quesada, Ana R.; Medina, Miguel Ángel; Martínez-Poveda, Beatriz (2020). A comparative study of the antiangiogenic activity of hydroxytyrosyl alkyl ethers. Food Chemistry, 333, 127476.

Medina, Miguel Ángel. "Imagen y ciencia". Paradigma, 2014, 16, 27-36.

Melgarejo, Esther; Medina, Miguel Ángel; Sánchez-Jiménez, Francisca; Urdiales, José LUis (2009). Epigallocatechin gallate reduces human monocyte mobility and adhesion in vitro. British Journal of Pharmacology, 2009, 1705-1712.

Modrego Rico, Aurelia (2018). La política científica en el atolladero. Investigación y Ciencia, 511, 60-67.

Quesada, Ana R.; Sánchez-Jiménez, Francisca; Pérez-Rodríguez, Josefa; Márquez, Javier; Medina, Miguel Ángel; Núñez de Castro, Ignacio (1988). Purification of phosphatedependent glutaminase from isolated mitochondria of Ehrlich ascites-tumour cells. Biochemical Journal, 255, 1'31-1036.

Radder, Hans, ed. (2010). The Commodification of Academic Research: Science and the Modern University. Pittsburgh: University of Pittsburgh Press.

Stenger, Isabelle (2017). Another Science is Possible. A Manifesto for Slow Science. Cambridge: Polity Press.

Ubellacker, Jessalyn M.; Tasdogan, Alpaslona; Ramsh, Vijayashree; Shen, Bo; Mitchell, Evann C.; Martín-Sandoval, Misty S.; Gu, Zhimin, McCormick, Michael L.; Durham, Alison 
B.; Spitz, Douglas R.; Zhao, Zhiyu; Mathews, Thomas P.; Morrison, Sean J. (2020). Lymph protects metastasizing melanoma cells from ferroptosis. Nature, 585, 114-119.

Van Valen, Leigh (1973). A new evolutionary law. Evolution Theory, 1, 1-3.

Watson, James D; Crick, Francis H.C (1953). Molecular structure of nucleic acids. A structure for deoxyribose nucleic acid. Nature, 171, 346. 